UDC: 615.22:616.1:351.84

DOI: 10.15587/2519-4852.2021.230346

\title{
RESEARCH OF THE EPIDEMIOLOGY ON CANCER OF THE TRACHEA, BRONCHI, LUNGS AS IMPORTANT COMPONENTS IN THE DEVELOPMENT OF EFFECTIVE DIRECTIONS FOR INCREASING THE EFFECTIVENESS OF PHARMACEUTICAL SUPPORT FOR CANCER PATIENTS
}

\author{
Yurii Pulnyi, Hanna Panfilova, Ellona Shelkova, Oleksandr Kabachnyi, Vitaly Chernukha
}

\begin{abstract}
The aim: to conduct epidemiological studies on cancer of the trachea, bronchi, lungs as important components in the development of effective directions for increasing the effectiveness of pharmaceutical support for cancer patients in Ukraine.
\end{abstract}

Materials and methods. The study used data from special literature, which presents the results of research on cancer in different countries of the world and data from the National Cancer Registry from 2014-2019 by indicators of morbidity and mortality of the population of Ukraine from cancer of the trachea, bronchi and lungs, including by gender. General theoretical (historical, analytical-comparative, systemic, graphic, logical, hypothetical-deductive) and applied (mathematical-statistical, epidemiological) research methods were used.

Results. It was found that during 2014-2018 in terms of morbidity and mortality of the population from cancer of the trachea, bronchi and lungs in Ukraine, there was a positive dynamics of decline. So, in terms of incidence rates, which are standardized by WHO in 2018, the data decreased compared to 2014 by $8.4 \%$, and according to the "Ukrainian standard" - by $7.0 \%$. Mortality rates, which were standardized by WHO, decreased in 2018 compared to 2014 by 12.1 $\%$, and those presented according to the "Ukrainian standard" - by $11.1 \%$. It was proved that the average data on morbidity and mortality of male patients were 6.2 and 7.4 times higher than in the same data for female patients. The different nature of changes in morbidity and mortality rates of patients in accordance with their gender in the dynamics of years has been established. So, for the female cohort of patients, the incidence and mortality rate from cancer of the trachea, bronchi and lungs during 2014-2018 had a complex zigzag character of changes, and in 2019, compared with the data of 2014, they increased by $22.54 \%$ and $23.6 \%$, respectively. In the male cohort of patients, we observed a positive trend towards a decrease in mortality during 2014-2019. So, in 2019, these indicators reached their minimum and were equal to 57.0 and 44.0 cases per 100 thousand population. According to the data of 2019, the incidence and mortality of men from cancer of the trachea, bronchi and lungs relative to the data of 2014 decreased by $21.4 \%$ and $25.0 \%$, respectively. It looks encouraging that there was relatively little fluctuation during 2014-2019 epidemiological indicators, both in general for the entire population of patients and female patients.

Conclusions. The established characteristics and trends in the formation of the onco-epidemiological profile of the country's population for trachea, bronchus and lung cancer in dynamics over the years necessitate further research, taking into account changes in the main demographic indicators development of society

Keywords: National Cancer Registry, oncoepidemiology, oncoepidemiological profile of the population of Ukraine, cancer of the trachea, bronchi and lungs, pharmaceutical provision of cancer patients

How to cite: Pulnyi, Y., Panfilova, H., Shelkova, E., Kabachnyi, O., Chernukha, V. (2021). Research of the epidemiology on cancer of the trachea, bronchi, lungs as important components in the development of effective directions for increasing the effectiveness of pharmaceutical support for cancer patients. ScienceRise: Pharmaceutical Science, 2 (30), 72-80. doi: http://doi.org/10.15587/2519-4852.2021.230346

(C) The Author(s) 2021

This is an open access article under the Creative Commons CC BY license

\section{Introduction}

Despite the significant advances in medicine and pharmacy, the issue of improving the effectiveness of treatment of cancer patients remains relevant for many countries $[1,2]$. The World Health Organization (WHO) is constantly updating epidemiological data on morbidity, mortality from cancer, and their structure over the years. According to WHO data, oncological pathologies are one of the leading causes of death in the world $[3,4]$. Thus, according to 2018, 9.6 million people died of cancer, and the leading position in the structure of mortality and prevalence is steadily occupied by lung cancer [3]. According to 2018, the first three positions in the structure of mortality were occupied by lung cancer (1.76 million cases), colon and rectum cancer, breast cancer (862 thousand deaths) and stomach cancer (783 thousand people). The three most common cancers include lung cancer
(2.09 million cases), breast cancer (2.09 million deaths), and colon and rectal cancer (1.80 million cases) [3]. According to epidemiological studies, the problem of the planned spread of lung cancer is characteristic of countries with different levels of socio-economic development $[5,6]$. Currently, thorough epidemiological studies on a set of etiological factors that have a direct impact on the development of oncological pathologies of the human respiratory system $[7,8]$. Given the increasing cost of early diagnosis $[9,10]$ and treatment of cancer patients $[11,12]$ of particular importance are studies to assess the impact of smoking on the incidence of lung cancer $[13,14]$, including depending on the sex [15], some demographic $[16,17]$ indicators and the presence of a burdensome history of patients [18]. The issues of increasing the effectiveness of prevention and early diagnosis of lung cancer are becoming increasingly important in the 
epidemiology of lung cancer [19, 20]. A promising direction in oncoepidemiological research is also the analysis of the influence of environmental factors on oncopathogenesis, primarily its contamination on the incidence and mortality of lung cancer [21, 22], as well as professional orientation and characteristics of certain segments of the population [23]. The results of all the above areas of epidemiological research form an objective basis for determining and forecasting the amount of funding for specialized health care institutions, insurance funds, as well as government programs aimed at financial support for cancer patients, including trachea, bronchi and lungs in case of medical and pharmaceutical care. In recent years, health care systems around the world have shown a steady trend towards a shortage of funds aimed at pharmaceutical supply of cancer patients who require the use of high-cost chemotherapy regimens for vital signs with strict adherence to their regimes in time $[11,12]$. Therefore, the results of epidemiological studies on the most common oncological pathologies form a scientifically sound basic basis for the development of areas of rational use of limited health resources. In addition, the data of epidemiological studies allow us to predict the loss of gross domestic product due to the planned increase in morbidity and mortality from the most common forms of cancer, which includes lung cancer. Studies of the oncoepidemiological profile of the population in the most common forms of cancer are especially relevant for Ukraine. As you know, currently the purchase of drugs for cancer patients in Ukraine is carried out with the help of international organizations. The resource constraints of this process under conditions of intensification of crisis phenomena in the economy necessitate the use of adequate indicators that characterize the oncological profile of the population. All mentioned above have led to our research.

The aim of the study was to conduct epidemiological studies on cancer of the trachea, bronchi, lungs as important components in the development of effective ways to improve the effectiveness of pharmaceutical care for cancer patients in Ukraine.

\section{Research planning (methodology)}

The outlined purpose of the study can be realized in the case of compliance and effective implementation of the following stages (Table 1).

Table 1

A plan for conducting applied research on this topic has been developed

\begin{tabular}{|c|c|}
\hline \multicolumn{2}{|c|}{ The name of the stage of the research } \\
\hline Contents of the research stage & Subjects of the research \\
\hline \multicolumn{2}{|c|}{ I stage - preparatory } \\
\hline $\begin{array}{l}\text { Substantiation of the relevance of research to solve a specific applied } \\
\text { problem, the solution of which should have some scientific and socio- } \\
\text { economic implications for improving the efficiency of medical and phar- } \\
\text { maceutical care of cancer patients under the existing health care resources. } \\
\text { Outline the purpose, objectives, goals, and subjects of the research. }\end{array}$ & $\begin{array}{l}\text { Data from the special literature containing the results of } \\
\text { modern epidemiological studies in various fields, as } \\
\text { well as analysis of morbidity, mortality and prevalence } \\
\text { of various forms of cancer in the world, including } \\
\text { Ukraine. }\end{array}$ \\
\hline
\end{tabular}

II stage - instrumental

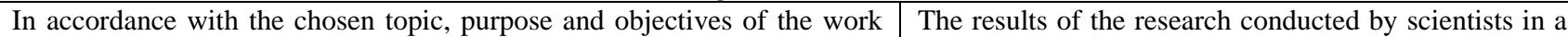
outlining the basic research methods and the necessary tools. Selection of a package of licensed software products that can be used at the preliminary stage of data processing and research results.

\section{III stage - analytical and statistical}

Analysis of statistical tables presented in the National Cancer Registry 1 NCR, Bulletin No. 21 by indicators of morbidity (con(NCR), Bulletin No. 21 on indicators that characterize the state of development of the epidemiological situation for cancer of the trachea, bronchi and lungs. Given the results of the analysis of special literature, which presents the results of epidemiological studies on the gender of patients $[15,16]$ promising, in our opinion, is the analysis of the cancer profile of cancer of the trachea, bronchi and lungs depending on the sex of the patient. Formation of analytical tables for selected forms of cancer in the dynamics of years. Statistical data processing and preliminary assessment of the reliability of the obtained results.

IV stage - analytical-synthetic

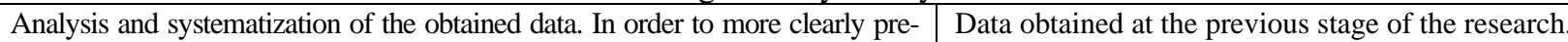
sent the results of research construction of graphic material. Estimation of tendencies of development of oncoepidemiological process in dynamics of years.

$\mathrm{V}$ stage - critical comprehension of the obtained results and possibilities of their practical use

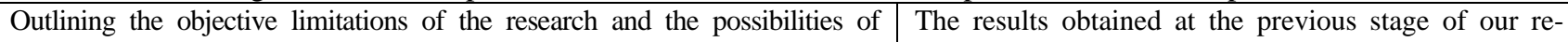
practical use of the obtained data to solve specific applications and problems in search.

the future. Critical review of data from the special literature, which provides data on the possibilities of epidemiological research in an alternative area.

\section{VI stage - effective and generalizing}

According to the systematization of the obtained data and taking into account the objective limitations of the research, the formulation of the main conclusions, as well as those areas that need further development and consideration, taking into account the medical-pharmaceutical and socioeconomic significance of the problem. Writing an article and preparing it for publishing.
The results obtained at all stages of our research are also data from the special literature, which outlines the directions of promising research that can be conducted in this direction, taking into account the influence of various external and internal factors in accordance with the selected object and research subjects. 


\section{Materials and methods}

The object of the research is the oncological profile of the population of Ukraine for tracheal, bronchial and lung cancer in Ukraine in the dynamics of years. The subject of the study - data from the special literature, which presents the results of the analysis of epidemiological indicators for the selected group of nosologies, as well as indicators of morbidity (indicator A) and mortality (indicator B) of the population of Ukraine from tracheal, bronchial and lung cancer in 2014-2019. We used epidemiological indicators that are standardized in the NCR ("Ukrainian standard") according to the sex and age structure of the population of Ukraine (2000), as well as those that are standardized by the WHO [24]. The analysis of the dynamics of changes in these epidemiological indicators was carried out using growth/decrease coefficients, growth rates $(\%)$ and growth (\%). In order to assess the fluctuations of epidemiological indicators in the dynamics of the years, the indicator of variation scale $\left(\mathrm{R}=\mathrm{X}_{\max }-\mathrm{X}_{\min }\right)$ was used, which was calculated in absolute and relative (\%) indicators [25]. In addition, we calculated the average chronological values $\left(\overline{\mathrm{Y}}=\left(\left(\mathrm{x}_{1}: 2\right)+\mathrm{x}_{2}+\ldots+\mathrm{x}_{\mathrm{n}-1}+\left(\mathrm{x}_{\mathrm{n}}: 2\right)\right): \mathrm{n}-1\right.$ in terms of morbidity $\left(\mathrm{A}_{\mathrm{av} . \mathrm{morb}}\right)$ and mortality $\left(\mathrm{B}_{\mathrm{av} . \mathrm{mor}}\right)$ population from tracheal, bronchial and lung cancer in Ukraine [25]. During the epidemiological research, general theoretical (historical, logical, comparative, graphic, hypothetical-deductive, etc.) and applied methods used in medical and pharmaceutical practice were used. A special place in the research was occupied by mathematical and statistical (method of comparing time series, bringing time series to the general indicator, identifying the general trend of time series, etc.), as well as epidemiological methods of analysis of actual indicators reflecting the oncological profile of the population nosologies.

Statistical data processing was performed using standard Statistica analysis packages (version 12.0, StatSoft, Tulsa, USA) and Excel spreadsheet.
A p-value $<0.05$ was considered as statistically significant.

\section{Research results}

According to the results of our research, we found

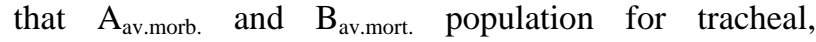
bronchial and lung cancer, which are standardized by the WHO were $22.5 \pm 0.06$ and $17.23 \pm 0.13$ cases per 100 thousand population. In fig. 1 . and 2 presents data on the incidence and mortality of patients with lung cancer in accordance with gender in countries with the world's highest onco-epidemiological data on this form of pathology [26]. It is noteworthy that our calculated Ukrainian indicators, which reflect the oncoepidemiological profile of the complex of pathologies (tracheal, bronchial and lung cancer) were much lower than in European countries such as Hungary, Serbia, Poland, France, Serbia and so on. Calculated data on epidemiological indicators, standardized by sex and age structure of the country's population ("Ukrainian standard") were equal to $33.02 \pm 0.05$ (A av.morb. ) and $25.60 \pm 0.03\left(\mathrm{~B}_{\text {av.mort }}\right)$. As we can see, the epidemiological indicators calculated according to the "Ukrainian standard" were higher than those standardized by the WHO.

Given the applied value of the use of epidemiological indicators in general for domestic health care in particular $[27,28]$ in the calculation of a number of financial indicators, the next stage of our research was to analyze the dynamics of changes in indicators A and B, presented according to the "Ukrainian standard". The results of the analysis are shown in Fig. 3. As we can see, these data fluctuated during 2014-2019 in the following range of values: indicator A - from 31.9 (2018) to 34.3 (2014) cases per 100 thousand population; indicator B from 24.1 (2018) to 27.1 (2014) persons per 100 thousand population. Thus, according to indicator $\mathrm{A}$, the variation range (\%) was $7.52 \%$, and according to indicator $\mathrm{B}-12.45 \%$.

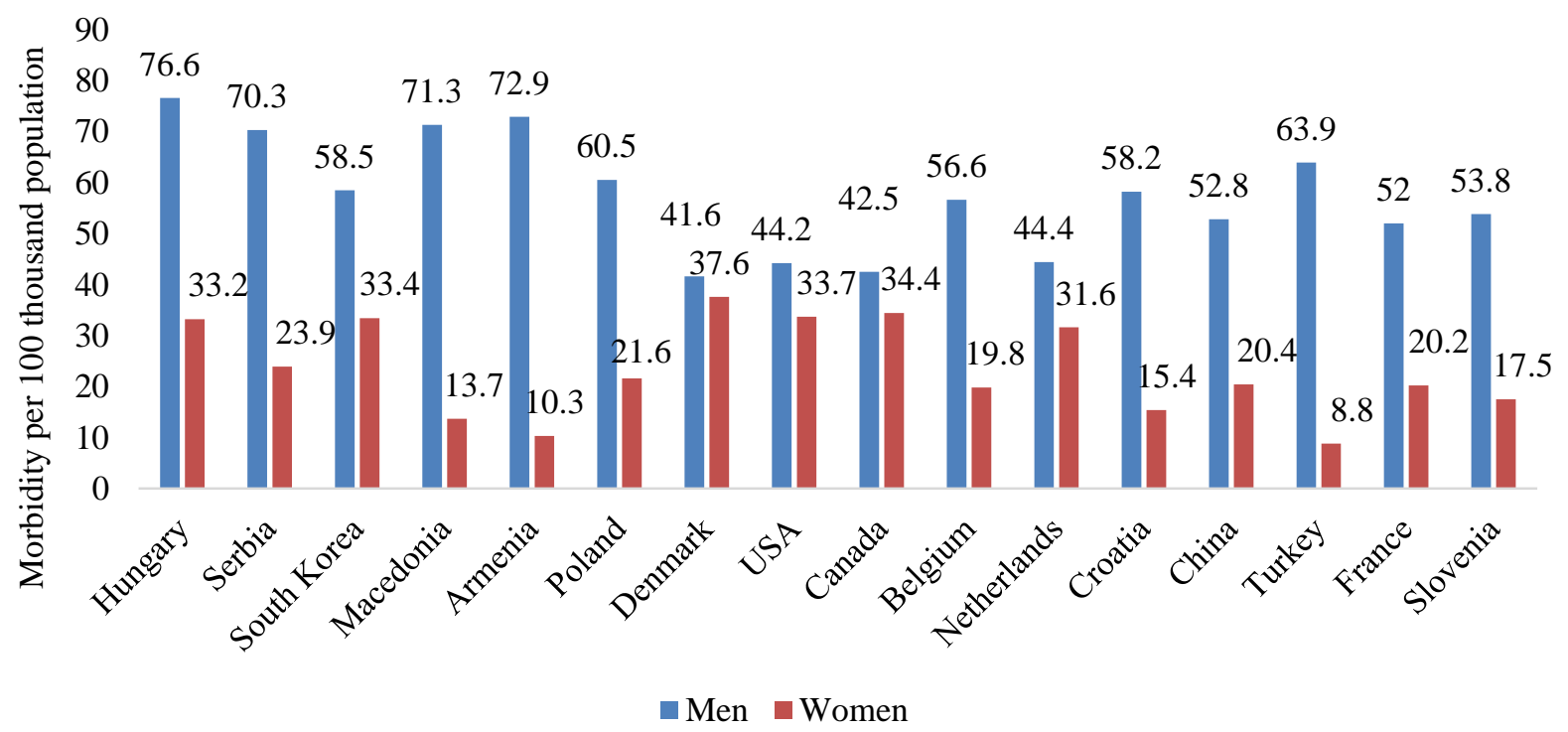

Fig. 1. The highest incidence rates of lung cancer in the world according to the gender of patients [26] 
The tendency to a systematic decrease in both epidemiological indicators during 2014-2018 is noteworthy. Thus, indicator A decreased from 34.3 to 31.9 cases (by $7.0 \%$ ), and B - from 27.1 to 24 , 1 thousand cases $(11.1 \%)$ per 100 thousand population, respectively. In the next 2019, indicator A increased compared to previous data by $4.1 \%$ and was equal to 33.2 cases per 100 thousand population, and indicator B by $5.4 \%$ (25.4 cases per 100 thousand population). In general, it can be argued that there is a positive trend (except for the data of 2017 for indicator A) to reduce the epidemiological indicators studied for five years, namely from 2014 to 2018 .
Given the results of epidemiological studies conducted by scientists on the incidence and mortality of lung cancer [16, 17], which occupies, certainly dominating the position in the structure of oncological pathologies affecting the upper and lower respiratory system, it is interesting to analyze the dynamics of changes in indicators $\mathrm{A}$ and $\mathrm{B}$ according to the sex of the patients. The results of the research are shown in Table 2 .

We will dwell in more detail on the analysis of changes in indicators $\mathrm{A}$ and $\mathrm{B}$ in accordance with the gender of patients with cancer of the trachea, bronchi and lungs.

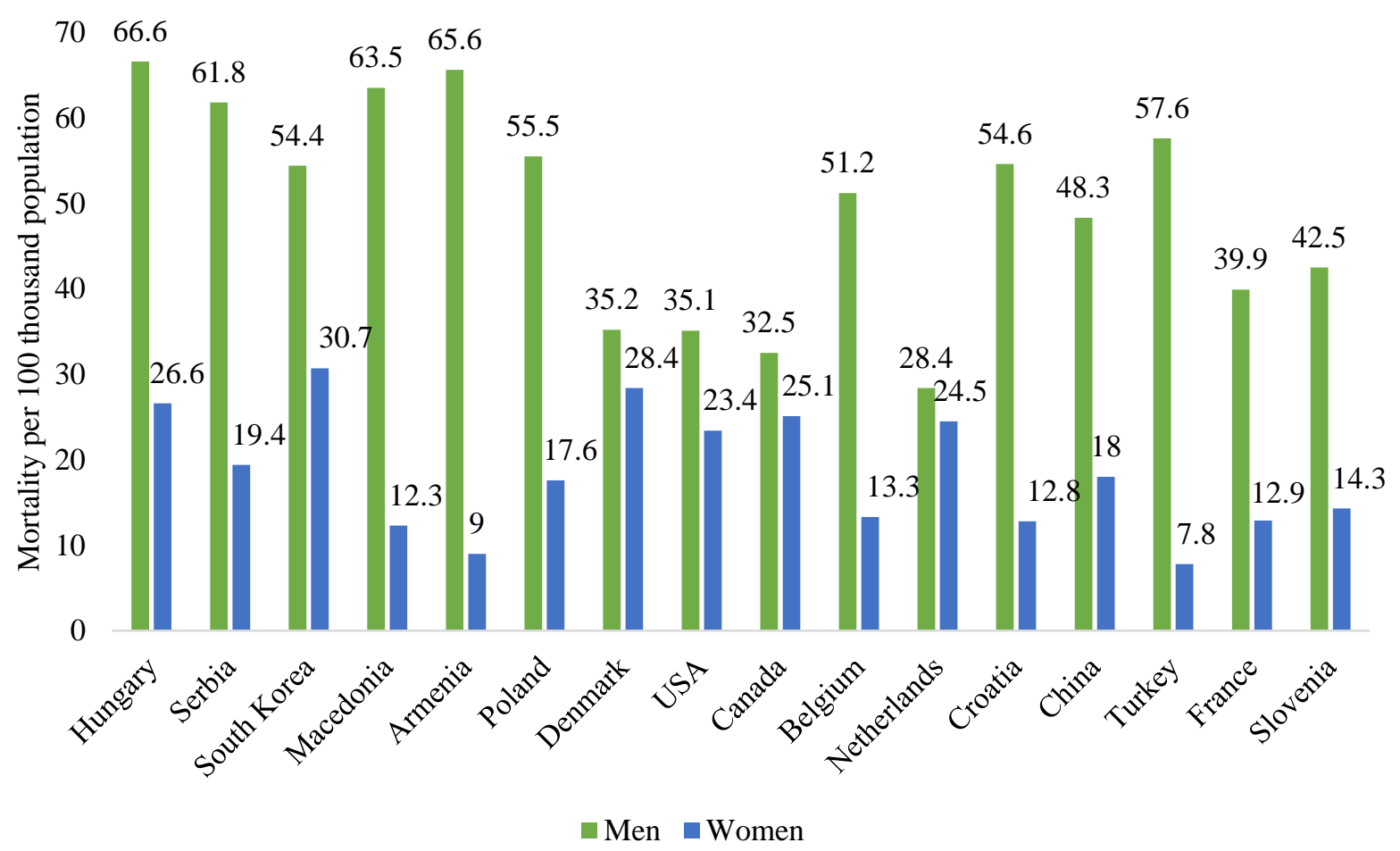

Fig. 2. Leading countries in terms of lung cancer mortality according to patients' gender [26]

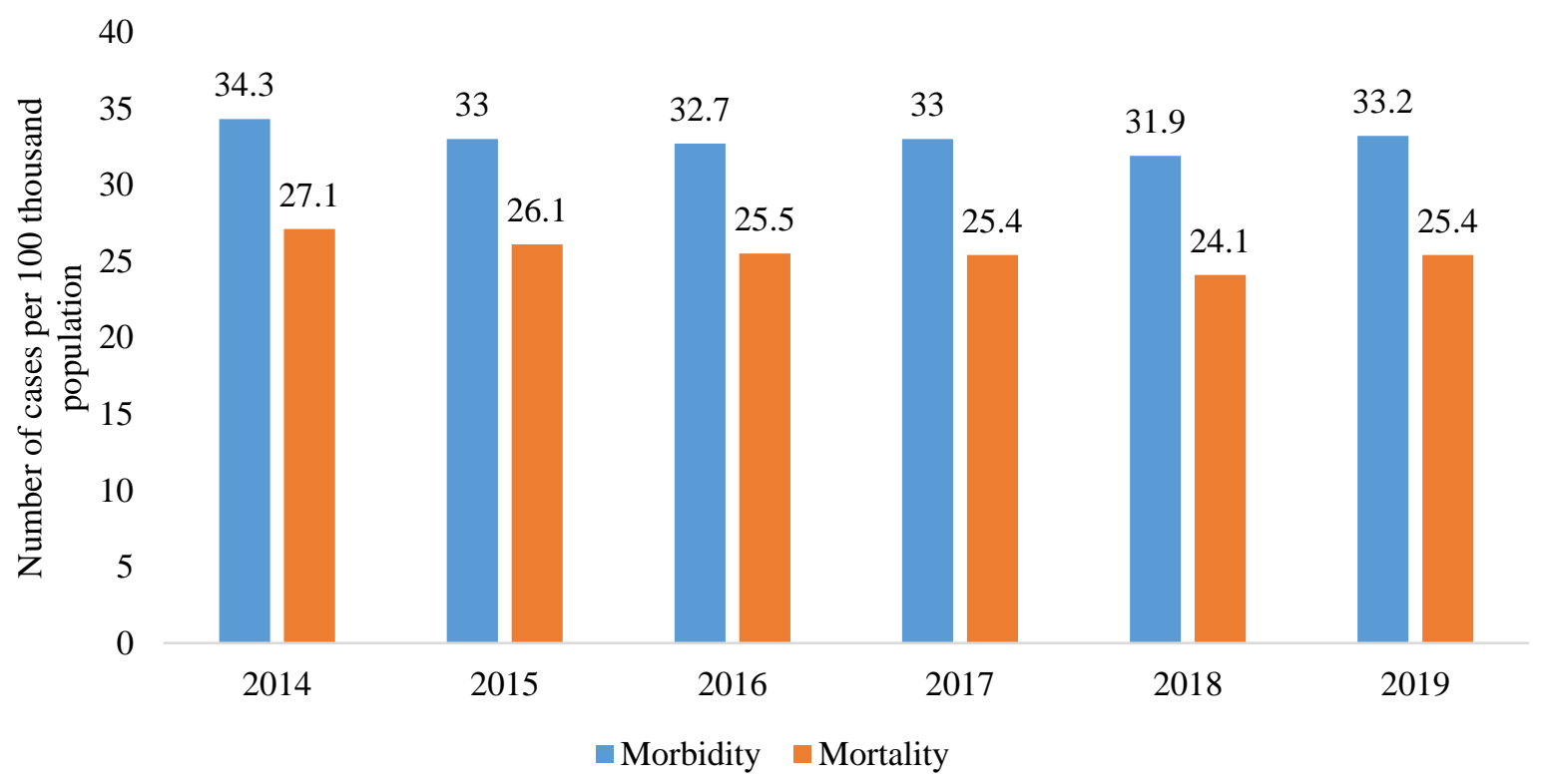

Fig. 3. Study of the dynamics of indicators A and B of the population of Ukraine ("Ukrainian standard") for tracheal, bronchial and lung cancer 
Analysis of the dynamics of changes in indicators A and B for 2014-2019 in Ukraine as a whole by population and by gender of patients

\begin{tabular}{|c|c|c|c|c|c|}
\hline \multicolumn{6}{|c|}{ Epidemiological indicators and results of their analysis by years } \\
\hline \multicolumn{6}{|c|}{ Indicator A, total population } \\
\hline 2014 & 2015 & 2016 & 2017 & 2018 & 2019 \\
\hline 34.3 & 33.0 & 32.7 & 33.0 & 31.9 & 33.2 \\
\hline \multicolumn{6}{|c|}{ Chain coefficients of growth / decrease of dynamics of indicator A } \\
\hline- & 0.96 & 0.99 & 1.01 & 0.97 & 1.04 \\
\hline \multicolumn{6}{|c|}{ Indicator B, total population } \\
\hline 27.1 & 26.1 & 25.5 & 25.4 & 24.1 & 25.4 \\
\hline \multicolumn{6}{|c|}{ Chain coefficients of growth / decrease of dynamics of indicator B } \\
\hline- & 0.96 & 0.98 & 0.99 & 0.95 & 1.05 \\
\hline \multicolumn{6}{|c|}{ Indicator A, total for the female cohort of patients } \\
\hline 10.2 & 10.2 & 10.7 & 10.5 & 11.0 & 12.5 \\
\hline \multicolumn{6}{|c|}{ Chain growth / reduction ratios of indicator A (women) } \\
\hline- & 1.0 & 1.05 & 0.98 & 1.05 & 1.14 \\
\hline \multicolumn{6}{|c|}{ Indicator B, total for the female cohort of patients } \\
\hline 7.2 & 6.8 & 6.9 & 7.0 & 6.8 & 8.9 \\
\hline \multicolumn{6}{|c|}{ Chain growth / reduction ratios of indicator B (women) } \\
\hline- & 0.94 & 1.02 & 1.02 & 0.97 & 1.31 \\
\hline \multicolumn{6}{|c|}{ Indicator A, total for the male cohort of patients } \\
\hline 72.5 & 69.3 & 67.7 & 68.9 & 65.3 & 57.0 \\
\hline \multicolumn{6}{|c|}{ Chain growth / reduction ratios of indicator A (men) } \\
\hline- & 0.96 & 0.98 & 1.02 & 0.95 & 0.87 \\
\hline \multicolumn{6}{|c|}{ Indicator B, total for the male cohort of patients } \\
\hline 58.7 & 56.8 & 55.3 & 54.9 & 52.0 & 44.0 \\
\hline \multicolumn{6}{|c|}{ Chain growth / reduction ratios of indicator B (men) } \\
\hline- & 0.97 & 0.97 & 0.99 & 0.95 & 0.85 \\
\hline
\end{tabular}

The value of $A_{\text {av.morb. }}$ in the group of female patients was equal to $10.85 \pm 0.07$, and for the group of male patients $-66.78 \pm 0.04$ per 100 thousand population. For $\mathrm{B}_{\text {av.mort. }}$ the value in the female cohort of patients was $7.27 \pm 0.08$ cases, and for men - 53.62 \pm 0.06 per 100 thousand population. Thus, the value of $\mathrm{A}_{\text {av.morb. }}$ in the group of male patients were 6.2 times higher than in the group of female patients. A similar dependence was observed for indicators $\mathrm{B}$, namely the value of $\mathrm{B}_{\text {av.mort. }}$ in men exceeded the corresponding figures for the group of female deaths 7.4 times.

Next, the nature of changes in indicators A and B by gender in the dynamics of the years was analyzed. It was found that the indicator A for the female population fluctuated during 2014-2019 in an insignificant range of values compared to similar data for the male group of patients. Thus, it ranged from 10.2 (2014-2015) to 12.5 cases (2019) per 100 thousand population, i.e. the variation range was $22.55 \%$. According to indicator A in the cohort of male patients, the variation range (minimum value was 57.0, and maximum - 72.5 cases per 100 thousand population) for the same period was equal to $27.19 \%$. The nature of changes in time of indicators $\mathrm{A}$ and $\mathrm{B}$ in the female and male cohort of patients is noteworthy. Thus, according to indicator A during 2014-2018 in the female cohort of patients, we observed a gradual increase in data (except in 2017), and among men, on the contrary - a decrease throughout the observation period. In addition, according to 2019 data among women there was an increase in data from indicator A, compared to the previous year by $13.64 \%$, and for men on the contrary - a decrease to 57.0 cases per 100 thousand population, i.e. by $12.71 \%$. That is, against the background of the general tendency of decrease of oncoepidemiological indicators on all population of patients with cancer of a trachea, bronchial tubes and lungs on female cohort of patients we observed their growth, and in group of male patients the return tendency to data decrease was observed. If we compare the data of 2019 with the data of 2014, we can say the following. Indicator A for the female population of patients increased by $22.5 \%$, and for the male on the contrary - decreased by $25.0 \%$.

As you know, indicator B is important not only from an epidemiological point of view. According to its analysis, the evaluation of the effectiveness of treatment of cancer patients in time and functioning of the entire oncology service of the country [29, 30]. According to indicator B in the female population of patients during 2014-2019 there was a zigzag nature of data changes, which cannot be said about similar data for a group of male patients. Thus, during the entire observation period, the B index in male patients systematically decreased, reaching its minimum according to 2019. As we see from Table 2, in 2019, the B index, compared to the previous 2018 decreased by $15.39 \%$. In general, it can be argued that the $\mathrm{B}$ indicators in the cohort of female patients in 2019 , compared to 2014 , increased by $23.61 \%$, and in men, on the contrary - decreased by $25.04 \%$. 


\section{Discussion of research results}

According to the conducted researches it is possible to define the following characteristic features which form an oncological profile of the population of Ukraine in dynamics of years on a cancer of a trachea, bronchial tubes and lungs. First, according to indicators $\mathrm{A}$ and $\mathrm{B}$, which are standardized by the $\mathrm{WHO}$ and the sex and age structure of the population ("Ukrainian standard"), we observed a positive trend to decrease the data (excluding indicators A for 2017). Another important characteristic of the oncology profile of the population of the country in these nosological groups is the presence of a significant difference between the values of epidemiological indicators in the female and male cohort of patients. So, the indicator $\mathrm{A}_{\text {av.mort. }}$ in the male population were 6.2 times, and according to $\mathrm{B}_{\text {av.morb. }}-7.4$ times higher than in the female group of cancer patients. At the same time, the presence of such a significant difference in epidemiological indicators is observed not only in Ukraine, but also in other countries [15, 31]. In the works of scientists, including domestic epidemiologists, every year more and more attention is paid to the analysis of the influence of various etiological factors on the development of oncological pathologies of the upper and lower respiratory tract in men and women. One of these areas is the study of the influence of the characteristics of professional activity of workers, including men on the oncoethiopathogenesis of cancer in general, and oncological pathologies of the trachea, bronchi and lungs in particular [32, 33]. The next important, in our opinion, the trend in the formation of the oncoepidemiological profile of the population for tracheal, bronchial and lung cancer in terms of gender of patients is the presence of different nature of changes in epidemiological indicators over time. Thus, in the female cohort of patients, indicator A was characterized by a complex, namely zigzag nature of changes in the data, while the values of indicators A in 2019 were higher than similar data in 2014 by $22.55 \%$. In the male cohort of patients, we observed the opposite trend, i.e. indicators A and B systematically decreased. However, in 2019 they reached their minimum and were equal to 57.0 cases per 100 thousand population, which were $21.38 \%$ lower than in 2014. According to indicator B, there were also different in nature trends in data over time by cohorts of patients in terms of their gender. Thus, during 2015-2016, the incidence of deaths from cancer of the trachea, bronchi and lungs decreased in women, and in 2019 we observed their increase compared to the previous period by $30.88 \%$, but also compared to similar indicators in 2014 - by $23.61 \%$. In the cohort of male patients, the number of deaths from this group of oncological pathologies had a positive tendency to gradually decrease and in 2019 amounted to 44.0 cases per 100 thousand population. In general, the fact of relatively small fluctuations in epidemiological indicators as a whole for the entire patient population and for female patients during 2014-2019 looks encouraging.

In conducting research, we used data presented on a single information platform (NCR), which contains onco-epidemiological indicators in Ukraine in the dynamics of years [24]. All other onco-epidemiological data encountered in the exposed information space during applied research were not taken into account by us, given the possibility of using different approaches to their collection and monitoring by scientists.

Study limitations. Given the fact that the results of epidemiological analysis form a scientifically sound basis for further research in various areas, important from a methodological point of view, is to outline the objective limitations of such work. This stage of applied research avoids systemic errors and unfounded conclusions in the case of scientific work in the future. So, first, it should be noted that the results of calculations $A_{\text {av.morb. }}$ and $\mathrm{B}_{\text {av.mort. }}$, as well as the dynamics of changes in indicators $\mathrm{A}$ and $\mathrm{B}$, both in the total population of patients and in terms of their gender did not take into account data on the Autonomous Republic of Crimea, Sevastopol and Donetsk and Luhansk regions. At the same time, it should be emphasized that in Donetsk and Luhansk regions until 2014 there were some of the highest, compared to other regions of the country, epidemiological rates of cancer of the trachea, bronchi and lungs [24]. It is clear that it is impossible to give an objective assessment of the situation in Ukraine with tracheal, bronchial and lung cancer without taking into account such important regions from the onco-epidemiological point of view. Therefore, we believe that the results obtained by us need further adjustment in accordance with the data that can be obtained in the territories of Donetsk and Luhansk regions, which are currently controlled by Ukraine. The second limitation of the research is related to the peculiarities of the formation of the NCR statistical base. Thus, for 2019, the NCR presents operational data, which in the next 2020 will be adjusted after appropriate processing and refinement. Therefore, we believe that in the course of further research it will be necessary to adjust the relevant epidemiological indicators according to the next edition of the NCR Bulletin No. 22, which will be presented at the end of this year. Given the different nature of changes in onco-epidemiological indicators over time in a cohort of male and female patients, we consider it necessary to point out the following limitation in our studies. In our opinion, it is necessary to conduct an additional study of changes in relevant oncoepidemiological indicators, which are presented in relative units (number of cases per 100 thousand population) by gender, taking into account changes in demographic indicators of the population. As it is known, the issue of disproportionate structural changes in the country's population on the basis of gender, especially with increasing age of women and men is an urgent demographic problem. And the fourth limitation, which did not allow us to conduct one of the most important areas of the research, namely the comparison of Ukrainian oncoepidemiological data with the corresponding indicators presented in different countries. This limitation is also due to the peculiarities of the formation of the statistical base of the NCR. Thus, NCR contains morbidity and mortality rates for a set of oncological pathologies that affect the upper and lower parts of the human respiratory system, namely cancer of the trachea, bronchi and lungs. Statistical data presented in the special literature on the analysis of the structure of morbidity and mortality from cancer contains a separate option - lung cancer [34, 35]. Assuming the fact that in the structure of indicators $\mathrm{A}$ and $\mathrm{B}$ the proportion (\%) of lung cancer is dominant, it 
would be possible to conduct a comparative analysis of relevant onco-epidemiological domestic and international data, especially by gender, but this would only be possible after a preliminary expert evaluation of the relevant statistics. Unfortunately, in the domestic special literature for the last 5-7 years we have not found data that highlight the state of the epidemiological situation of lung cancer in general by population, as well as in accordance with the gender of patients or territorial division of the country. Despite the outlined objective limitations in our research, we believe that they can be used to quickly assess the development of the oncoepidemiological situation in cancer of the trachea, bronchi and lungs, and also allow to characterize the oncoepidemiological profile of the population by this group of pathologies. In addition, the outlined objective limitations allow to adequately interpret and use the obtained results, as well as to form the directions of perspective researches in the specified direction.

Prospects for further research. Areas of prospective research on this topic are due on the one hand to the permanent relevance of the issue under consideration, and on the other - the nature of the results we have obtained and the limitations in their practical use, outlined above. So we believe that the main directions in conducting further research on this topic may be:

- analysis of indicators A and B in the dynamics of years by different administrative-territorial units of the country in order to determine the regional features of the onco-epidemiological situation of cancer of the trachea, bronchi and lungs;

- study of changes in indicators A and B in accordance with the changes in the sex and age structure of the population of the country, which occurred in the population during 2014-2019, especially during the period 2014-2015;

- given the significant dependence of epidemiological indicators on a range of external factors, such as place of residence [36, 37], the peculiarities of professional activity $[14,32]$, the state of environmental pollution $[22,23]$, which are presented in the literature [14, $22]$ it is relevant to conduct research on target groups of cancer patients;

- forecasting indicators A and B in the country as a whole, as well as in terms of its administrative- territorial distribution and by groups of patients and by gender of patients.

\section{Conclusions}

Despite the many difficulties associated with the process of reforming the domestic health care system and pharmaceutical supply, Ukraine is confidently moving towards the introduction of socially oriented forms and methods of providing patients with affordable medical and pharmaceutical care. Given the permanent nature of the deficit of funds in the state, an important condition for the effective implementation of these measures is the introduction of rational mechanisms for resource allocation. Peculiarities of the development of the epidemiological situation of tracheal, bronchial and lung cancer should be taken into account in the development of state and regional programs of early prevention, effective treatment and further social rehabilitation of cancer patients. The established characteristics and trends of changes in the formation of the oncoepidemiological profile of the population of the country with cancer of the trachea, bronchi and lungs in the dynamics of the years suggest the need for further research to take into account changes in key demographic indicators. In addition, the results of monitoring indicators $\mathrm{A}$ and $\mathrm{B}$ can be used in making effective management decisions regarding the reorganization of the oncology service in Ukraine, which now also needs systemic reform due to changes in its funding and increasing public demand for medical pharmaceutical care.

\section{Conflict of interests}

The authors declare that they have no conflicts of interest.

\section{Acknowledgment}

We consider it necessary to express our gratitude to the staff of the Department of Cancer Epidemiology of the National Cancer Institute (NCI), as well as scientists who were at the origins of the NCR in 1989 on the basis of the Ukrainian Research Institute of Oncology and Radiology (NCI). Through the efforts of R\&D scientists in Ukraine, work was initiated to implement a software and information system for cancer registration, which brought its operation to a fundamentally new level of information, which, in turn, allowed to conduct thorough theoretical and applied research in various areas of oncology.

\section{References}

1. Khajedaluee, M., Dadgarmoghaddam, M., Saeedi, R., Izadi-Mood, Z., Abrishami, M., Zamani, M. (2014). Mortality, Morbidity, Survival, and Burden of Top 9 Cancers in a Developing Country. Razavi International Journal of Medicine, 2(3). doi: http://doi.org/10.5812/rijm.20073

2. Ferlay, J., Steliarova-Foucher, E., Lortet-Tieulent, J., Rosso, S., Coebergh, J. W. W., Comber, H. et. al. (2013). Cancer incidence and mortality patterns in Europe: Estimates for 40 countries in 2012. European Journal of Cancer, 49 (6), $1374-1403$. doi: http://doi.org/10.1016/j.ejca.2012.12.027 15.03.2021

3. WHO. Cancer. Key Facts. Available at: https://www.who.int/news-room/fact-sheets/detail/cancer Last accessed:

4. Bray, F., Ferlay, J., Soerjomataram, I., Siegel, R. L., Torre, L. A., Jemal, A. (2018). Global cancer statistics 2018: GLOBOCAN estimates of incidence and mortality worldwide for 36 cancers in 185 countries. CA: A Cancer Journal for Clinicians, 68 (6), 394-424. doi: http://doi.org/10.3322/caac.21492

5. Fang, J.-Y., Dong, H.-L., Wu, K.-S., Du, P.-L., Xu, Z.-X., Lin, K. (2015). Characteristics and Prediction of Lung Cancer Mortality in China from 1991 to 2013. Asian Pacific Journal of Cancer Prevention, 16 (14), 5829-5834. doi: http://doi.org/10.7314/ apjcp.2015.16.14.5829 
6. Brenner, D. R., Boffetta, P., Duell, E. J., Bickeboller, H., Rosenberger, A., McCormack, V. et. al. (2012). Previous Lung Diseases and Lung Cancer Risk: A Pooled Analysis From the International Lung Cancer Consortium. American Journal of Epidemiology, 176 (7), 573-585. doi: http://doi.org/10.1093/aje/kws151

7. Hüsing, A., Kaaks, R. (2020). Risk prediction models versus simplified selection criteria to determine eligibility for lung cancer screening: an analysis of German federal-wide survey and incidence data. European Journal of Epidemiology, 35 (10), 899 912. doi: http://doi.org/10.1007/s10654-020-00657-w

8. Gray, E. P., Teare, M. D., Stevens, J., Archer, R. (2016). Risk Prediction Models for Lung Cancer: A Systematic Review. Clinical Lung Cancer, 17 (2), 95-106. doi: http://doi.org/10.1016/j.cllc.2015.11.007

9. Becker, N., Motsch, E., Gross, M.-L., Eigentopf, A., Heussel, C. P., Dienemann, H. et. al. (2015). Randomized Study on Early Detection of Lung Cancer with MSCT in Germany: Results of the First 3 Years of Follow-up After Randomization. Journal of Thoracic Oncology, 10 (6), 890-896. doi: http://doi.org/10.1097/jto.0000000000000530

10. De Koning, H. J., van der Aalst, C. M., de Jong, P. A., Scholten, E. T., Nackaerts, K., Heuvelmans, M. A. et. al. (2020). Reduced Lung-Cancer Mortality with Volume CT Screening in a Randomized Trial. New England Journal of Medicine, 382 (6), 503-513. doi: http://doi.org/10.1056/nejmoa1911793

11. Zhong, Y. J., Wen, Y. F., Wong, H. M., Yin, G., Lin, R., Yang, S. Y. (2019). Trends and Patterns of Disparities in Burden of Lung Cancer in the United States, 1974-2015. Frontiers in Oncology, 9. doi: http://doi.org/10.3389/fonc.2019.00404

12. Albreht, T., Martin-Moreno, J. M., Jelenc, M., Gorgojo, L., Harris, M. (Eds.) (2015). European Guide for Quality National Cancer Control Programme. Ljubljana, 113.

13. Thun, M. J., Carter, B. D., Feskanich, D., Freedman, N. D., Prentice, R., Lopez, A. D. et. al. (2013). 50-Year Trends in Smoking-Related Mortality in the United States. New England Journal of Medicine, 368 (4), 351-364. doi: http://doi.org/10.1056/nejmsa1211127

14. Ferreccio, C., Yuan, Y., Calle, J., Benítez, H., Parra, R. L., Acevedo, J. et. al. (2013). Arsenic, Tobacco Smoke, and Occupation. Epidemiology, 24 (6), 898-905. doi: http://doi.org/10.1097/ede.0b013e31829e3e03

15. Torre, L. A., Siegel, R. L., Ward, E. M., Jemal, A. (2014). International Variation in Lung Cancer Mortality Rates and Trends among Women. Cancer Epidemiology Biomarkers \& Prevention, 23 (6), 1025-1036. doi: http://doi.org/10.1158/1055-9965.epi-13-1220

16. Chien, L.-H., Chen, C.-H., Chen, T.-Y., Chang, G.-C., Tsai, Y.-H., Hsiao, C.-F. et. al. (2019). Predicting lung cancer occurrence in never-smoking females in Asia: TNSF-SQ, a prediction model. Cancer Epidemiology Biomarkers \& Prevention, 29 (2), 452-459. doi: http://doi.org/10.1158/1055-9965.epi-19-1221

17. Nakamura, H., Ando, K., Shinmyo, T., Morita, K., Mochizuki, A., Kurimoto, N., Tatsunami, S. (2011). Female Gender Is an Independent Prognostic Factor in Non-small-cell Lung Cancer: A Meta-analysis. Annals of Thoracic and Cardiovascular Surgery, 17 (5), 469-480. doi: http://doi.org/10.5761/atcs.oa.10.01637

18. De Torres, J. P., Marín, J. M., Casanova, C., Cote, C., Carrizo, S., Cordoba-Lanus, E. et. al. (2011). Lung Cancer in Patients with Chronic Obstructive Pulmonary Disease. American Journal of Respiratory and Critical Care Medicine, 184 (8), $913-919$. doi: http://doi.org/10.1164/rccm.201103-0430oc

19. Infante, M., Cavuto, S., Lutman, F. R., Passera, E., Chiarenza, M., Chiesa, G. et. al. (2015). Long-Term Follow-up Results of the DANTE Trial, a Randomized Study of Lung Cancer Screening with Spiral Computed Tomography. American Journal of Respiratory and Critical Care Medicine, 191 (10), 1166-1175. doi: http://doi.org/10.1164/rccm.201408-1475oc

20. Yang, D., Liu, Y., Bai, C., Wang, X., Powell, C. A. (2020). Epidemiology of lung cancer and lung cancer screening programs in China and the United States. Cancer Letters, 468, 82-87. doi: http://doi.org/10.1016/j.canlet.2019.10.009

21. Hamra, G. B., Guha, N., Cohen, A., Laden, F., Raaschou-Nielsen, O., Samet, J. M. et. al. (2014). Outdoor Particulate Matter Exposure and Lung Cancer: A Systematic Review and Meta-Analysis. Environmental Health Perspectives, 122 (9), $906-911$. doi: http://doi.org/10.1289/ehp/1408092

22. Raaschou-Nielsen, O., Andersen, Z. J., Beelen, R., Samoli, E., Stafoggia, M., Weinmayr, G. et. al. (2013). Air pollution and lung cancer incidence in 17 European cohorts: prospective analyses from the European Study of Cohorts for Air Pollution Effects (ESCAPE). The Lancet Oncology, 14 (9), 813-822. doi: http://doi.org/10.1016/s1470-2045(13)70279-1

23. Vermeulen, R., Silverman, D. T., Garshick, E., Vlaanderen, J., Portengen, L., Steenland, K. (2014). Exposure-Response Estimates for Diesel Engine Exhaust and Lung Cancer Mortality Based on Data from Three Occupational Cohorts. Environmental Health Perspectives, 122 (2), 172-177. doi: http://doi.org/10.1289/ehp.1306880

24. National Cancer Registry of Ukraine: short description of the database (2020). Cancer in Ukraine 2018-2019. Available at: http://www.ncru.inf.ua/publications/

25. Fang, J.-Q. (Ed.) (2017). Handbook of Medical Statistics. Sun Yat-Sen University, 852. doi: http://doi.org/10.1142/10259

26. Barta, J. A., Powell, C. A., Wisnivesky, J. P. (2019). Global Epidemiology of Lung Cancer. Annals of Global Health, 8 5(1). doi: http://doi.org/10.5334/aogh.2419

27. Jemal, A., Bray, F., Forman, D., O’Brien, M., Ferlay, J., Center, M., \& Parkin, D. M. (2012). Cancer burden in Africa and opportunities for prevention. Cancer, 118 (18), 4372-4384. doi: http://doi.org/10.1002/cncr.27410

28. Shushpanov, D. G. (2016). Causes and determinants of ultrahigh mortality in Ukraine: comparative social and demographic analysis with the European Union countries. Economic analysis, 23 (1), 111-122.

29. De Groot, P. M., Wu, C. C., Carter, B. W., Munden, R. F. (2018). The epidemiology of lung cancer. Translational Lung Cancer Research, 7 (3), 220-233. doi: http://doi.org/10.21037/tlcr.2018.05.06

30. Zheng, W., Zhang, H., Shen, C., Zhang, S., Wang, D., Li, W., Jiang, G. (2020). Trend analysis of lung cancer mortality and years of life lost (YLL) rate from 1999 to 2016 in Tianjin, China: Does the lung cancer burden in rural areas exceed that of urban areas? Thoracic Cancer, 11 (4), 867-874. doi: http://doi.org/10.1111/1759-7714.13314

31. Liang, F., Wu, C., Gu, H., Zhu, M., Xuan, Z., Jiang, Y. et. al. (2019). Lung cancer incidence in female rises significantly in urban sprawl of Shanghai after introduction of LDCT screening. Lung Cancer, 132, 114-118. doi: http://doi.org/10.1016/j.lungcan.2019.04.020

32. Lebed, O. O., Trusheva, S. S., Lysytsya, A. V. (2019). Impact of radon exposure upon dynamics of mortality rate from lung cancer for population of Rivne city, Ukraine. Ukrainian Journal of Ecology, 9 (1), 25-34.

33. Shvaiko, L., Sushko, V., Bazyka, K. (2013). Lung cancer cases in clean-up workers of Chernobyl NPP accident. European Respiratory Journal, 42 (5742), 4503. Available at: https://erj.ersjournals.com/content/42/Suppl_57/P4503.article-info Last accessed: 15.02.2021

34. Islami, F., Torre, L. A., Jemal, A. (2015). Global trends of lung cancer mortality and smoking prevalence. Transl Lung Cancer Res, 4 (4), 327-338. 
35. Siegel, R. L., Miller, K. D., Jemal, A. (2020). Cancer statistics, 2020. CA: A Cancer Journal for Clinicians, 70 (1), 7-30. doi: http://doi.org/10.3322/caac.21590

36. Yang, J., Zhu, J., Zhang, Y.-H., Chen, Y.-S., Ding, L.-L., Kensler, T. W., Chen, J.-G. (2015). Lung Cancer in a Rural Area of China: Rapid Rise in Incidence and Poor Improvement in Survival. Asian Pacific Journal of Cancer Prevention, 16 (16), 7295 7302. doi: http://doi.org/10.7314/apjcp.2015.16.16.7295

37. Pinsky, P. F., Church, T. R., Izmirlian, G., Kramer, B. S. (2013). The National Lung Screening Trial: Results stratified by demographics, smoking history, and lung cancer histology. Cancer, 119 (22), 3976-3983. doi: http://doi.org/10.1002/cncr.28326

Received date 11.03.2021

Accepted date 21.04.2021

Published date 30.04.2021

Yurii Pulnyi, Postgraduate Student, Department of Organization and Economics of Pharmacy. National University of Pharmacy, Pushkinska str., 53, Kharkiv, Ukraine, 61002

E-mail: dachnoit@gmail.com

Hanna Panfilova, Doctor of Pharmaceutical Sciences, Professor, Department of Organization and Economics of Pharmacy, National University of Pharmacy, Pushkinska str., 53, Kharkiv, Ukraine, 61002

E-mail: panf-al@ukr.net

Ellona Shelkova, PhD, Leading Consultant on Evidence-Based Medicine, Director of Center, Center for Professional Harmonization "Reforma ZOZ", Borysa Hmyri str., 2, Kyiv, Ukraine, 02140

E-mail: eshelkovaya@gmail.com

Oleksandr Kabachnyi, PhD, Leading Consultant on Evidence-Based Medicine, Center for Professional Harmonization "Reforma ZOZ", Borysa Hmyri str., 2, Kyiv, Ukraine, 02140

E-mail: aleksander.kabachny@gmail.com

Vitaly Chernukha, PhD, Associate Professor, Department of Organization and Economics of Pharmacy, National University of Pharmacy, Pushkinska str., 53, Kharkiv, Ukraine, 61002

E-mail: vitaly1963@ukr.net 